\section{A COMPLEX CONCEPTION OF MANAGEMENT SYSTEM OF ORGANISATIONS AND SOCIAL RESPONSIBILITY \\ VERA PELANTOVA ${ }^{1}$, DOMINIK KOLAR ${ }^{2}$}

${ }^{1}$ Faculty of Mechatronics, Informatics and Interdisciplinary Studies, MTI, Liberec

${ }^{2}$ Faculty of Mechatronics, Informatics and Interdisciplinary Studies, MTI, Liberec

Technical university of Liberec, Czech Republic

DOI: 10.17973/MMSJ.2021_12_2021028

vera.pelantova@tul.cz

The difficult situation is affecting many organisations at the present time. This article mainly deals with ensuring of the quality of production on the example of a case study in one manufacturing organisation. However, it is about involving other aspects, such as: maintenance, social responsibility, process approach. Everything is based on specific findings related to the economic crisis caused by the COVID-19 pandemic. Quality management tools and responsibility tools were applied in solving this complex task. The example of the mentioned organisation shows that the conformity application of aspects of the management system above in a holistic connection to soft resources not only supports the strengthening of production quality and the growth of efficiency, but it also strengthens an internal culture of the organisation. The goal is to ensure an efficient operation of the organisation and thus to support its competitiveness.

KEYWORDS

Social Responsibility; Quality; Maintenance; Management System; Industry 4.0; Production; Organisation.

\section{INTRODUCTION}

A quality of production is the basis of management system of every organisation. It turns out to be a basic pillar of development of the organisation in the future. It is followed by management systems: occupational safety, environment, information security, accounting, and maintenance. However, organisations often face several nonconformities, where a poor quality of production is only a consequence of their status quo. Therefore, a holistic view of management system of the organisation seems to be an important area, which offers other necessary parts to build a truly functioning whole. Social responsibility seems to be a key part but often a neglected one. It deals with a common element of the organisation's system that is not at the centre of improvement. It will therefore be given more attention.

\section{LITERATURE REVIEW ON THE COMPREHENSIVE CONCEPT OF THE MANAGEMENT SYSTEM}

Management systems are commonly researched and described in publications. The basis of management systems is the quality system according to ISO 9001 or the TQM concept. The standard ISO 9001 [ISO 9001] describes the framework of the system and deals more with production, business, and administrative aspects. The TQM concept is more complex in this respect. It involves people more in the management system of the organisation. But even there it does not cover all the soft aspects. Therefore, social responsibility has been included among management systems.

For this very purpose, a standard ISO 26000 has been developed. This norm is in accordance with the existing quality management, as mentioned in the article [Castka 2008]. The standard ISO 26000 [ISO 26000] describes the relationship of the organisation to the public and the substantial neighbourhood as a factor in its effective functioning and performance. It facilitates the transition to perceiving the needs of all stakeholders and it helps to determine the strategy of the organisation, as it is written in publications [Castka 2008] and [ISO 26000]. There are 4 pillars of the social responsibility (workplace, market, environment, and the public), which are not a policy implementation, according to the text [Duff 2017]. This is also supported by the publication [Martinuzzi 2013], which focuses on a strategy management, a quality, projects, and an organisational learning. The first 3 pillars are quite described in publications. The organisation learning and change are only marginally touched. At the same time, this part helps the social responsibility to be systematically applied in a dynamic substantial environment. The approach of organisations is often limited to the life cycle of product, the care of human resources and respect for the operating license according to the publication [Martinuzzi 2013]. The article [Holgado 2020] examines the relationship between the social responsibility, environment, the maintenance, and production. According to [Drozyner 2020] the maintenance includes items of environment, human safety, quality of production and efficiency. In addition to technical aspects, it connects economic, legislative, and organisational aspects. The aim is to keep the sustainability in relation to the possibility of change and safety according to the text [Bruno 2020] and thus to create a policy in this area. The text [Thai 2018] examines the relationship between the social responsibility and the quality of services to a job satisfaction, a customer satisfaction, and a financial effect on organisations. According to the document [Martinuzzi 2013], organisations approach the social responsibility in 4 ways: projecting of goodness in a certain area, avoiding of evil, looking for opportunities to share values and the overcoming of limitations of an organisation's capabilities.

Many publications examine the applicability of the social responsibility in organisations as well and in society from different perspectives and on different examples. Some of them follow. The article [Castka 2008] deals with a system concept of the standard ISO 26000 [ISO 26000]. The article [Duff 2017] examines components of the social responsibility and its connection with strategy of the organisation on the example of accounting organisations. The article [Gruntova 2015] sees as a fundamental the management of performance of the organisation. The text [Drozyner 2020] examines the relationship of the social responsibility to an integrated system in relation to the maintenance in the organisation. The article [Rakyta 2014] deals with the relationship among an increasing of production efficiency with respect to an equipment maintenance management and a logistic of spare parts. The article [Holgado 2020] focuses on simple life cycle of an equipment. The study of maintenance management in the IT area in relation to the Industry 4.0 is linked to a maintenance strategy and to a system framework by the text [YunusaKaltungo 2021]. The text [Bruno 2020] examines the transition to sustainable transport systems through the social responsibility and the maintenance. They show the whole industry in relation to a human transient of life events in 
a cycling example. The publication [Yee 2020] highlights change and demands of a work environment in relation to the quality of a person's working life. The text [Thai 2018] researches examples of logistics of organisations. The text [Toussaint 2020] examines the area of social responsibility de facto on an example of the state's health care, which it must be taken as a service form of product.

According to the article [Duff 2017], the emphasis is on social and environmental communication. Motivations of parties are examined. Some areas of the economy and some sections of the population are more sensitive to the social responsibility. Employees need to be supported. The crucial factor is called "feeling good". These are parts of social responsibility that are not directly linked to customers. Publications, such as the text [Yee 2020], address demands of a person's working life. It deals with independence of the employee, integration into the workplace, remuneration, conditions of the workplace and integration into the organisation. The key is the employee's perception of work regarding balancing, opportunities, benefits, and health \& safety. This research is based on a qualitative analysis. The result is that a work life and a personal life of human are inseparable, the book [Pelantova 2014] states that as well. From this derives the satisfaction or the turnover of employees according to publications [Yee 2020] and [Thai 2018]. Significant factors are the integration into the organisation and the remuneration. Most of original researches, according to the text [Yee 2020], deal with external stakeholders, but the key ones are really employees and hence the local community. It turns out that employees need to perceive a social support from their organisation. This is more important to them than the existence of management policies. In addition, the employee may be satisfied with remunerations, but not with other aspects. They perceive workplace conditions and their independence better than integration into the workplace, remuneration and integration into the organisation. Diversity also plays a role. The text [Thai 2018] states that quality services and the introduction of social responsibility lead not only to customer satisfaction, but also compensate employee's satisfaction with a job. It was proven also that emotions are transmitted among stakeholders. It is the same as that the social responsibility and the quality management complement each other. The article [Rakyta 2014] notes that the maintenance must consider requirements of customers and shareholders. The influence of communities on the so-called moral legitimacy, which is more demanding than a simple trade according to text [Duff 2017], is also significant. The text [Bruno 2020] proves seemingly small risk of young men in the transport system. However, the reduction of risks in cycling therefore depends on the development of ways and increasing their safety, and on the innovation and the maintenance of bicycles as well as the maintenance of people's health. This must be integrated as overall sustainability into a policy that it provides a financial support. The text [Toussaint 2020] solves the increase of satisfaction of patients and healthcare employees by combining the $M$. Baldridge's model of excellence with the Shingo method.

The article [Holgado 2020] recommends not wasting of materials and of energy. It relates the maintenance and the safety of work. It takes the phase of equipment disposal quite strictly regarding the change of production needs, in contrast to the document on the paper mill [Author1 2020], where they emphasize the use of old renovated equipment as well. The article [Rakyta 2014] sees the productivity because of efficiency of processes, which is based on the evaluation of the maintenance's indicators and the use of tools to determine the criticality of spare parts (such as the ABC method).

The evidence of relationship between the social responsibility and problems of a financial reporting, especially in 2009 year, was not found according to the text [Duff 2017]. The text [Thai 2018] states that the relationship between the social responsibility and financial performance does not bring clear results. The publication [Martinuzzi 2013] points out actions to the social responsibility, which are provided only if at least one of the actors requires it. Otherwise, they see them only as a cost pressure. According to the text [Drozyner 2020], it shows that an organisation with a high culture does not perceive management systems as cost items, it supports innovations, develops employee competencies, and considers requirements of stakeholders. The article [Yunusa-Kaltungo 2021] looks at the matter in a similar way. According to the text [Bruno 2020]), a simple cost analysis and a benefit assessment does not correspond to a maintenance-based approach. The article [Gruntova 2015] points out that the organisation must take actions to increase its performance and to strengthen the strategy and the measurement of indicators to improve the overall result.

Research show that the social responsibility is taken marginally, not as a means of strengthening legitimacy in a crisis. The influence of managers on the social responsibility seems less obvious. A generational gap among groups seems a problematic, because this interaction has not brought anything for some individuals. Organisations that do not control financial markets feel their handicap that they do not regulate this market, as for example the article [Duff 2017] evidences. The state or regulatory institutions are important opponents for many actors, as the document [Martinuzzi 2013] states. This also reinforces the impact of a financial crisis and a widening gap between rich and poor people in general. The text [YunusaKaltungo 2021] points to problems with a stakeholders' intellectual property, a big data, and their security and so on due to unresolved issues in organisations. The text [Thai 2018] describes those stakeholders perceive the social responsibility by different way. They use for a decision making their priorities and the impact of activities on economy of the organisation. The text [Toussaint 2020] points out the lack of a holistic management system and the lack of indicators and values to improve the management system for the health care, which is provided.

The following text describes limitations and the future of this area in organisations. It is necessary in example of one organisation to verify the view of all stakeholders (customers, employees, communities, and other external subjects) and to examine their relationship to the strategy of organisation, as the text [Duff 2017] offers. It is also necessary to examine who practitioners of the social responsibility in organisations are, what their qualification is, what main characteristics are. The research should deal with the maintenance of employees, effects of characteristics of a working life on a personal life, effects of the employee's gender and so on, according to the article [Yee 2020]. A knowledge base in organisations should be the core due to changes in the world. There is a need to highlight ethics in organisations and to examine its relationship with the social responsibility. This is needed especially in the field of accounting as the text [Duff 2017] mentioned. The publication [Martinuzzi 2013] recommends developing a valuable model of maturity of the social responsibility with indicators and a method for assessing the maturity of an industry, to collect knowledge of unforeseen events and to set an area of limitations and transitional rules among phases of 
the social responsibility. Texts [Yunusa-Kaltungo 2021] and [Thai 2018] recommend examining of the social responsibility in different fields and countries. Previous studies do not focus on end customers, they do not consider the type of production, of organisational structure and of value orientation of organisations. The causal link between the quality management and the social responsibility should be examined. The improvement of the management system of organisations should be supported by legislative bodies of the country by the text [Toussaint 2020]. The article [Holgado 2020] proposes to study a carbon footprint in the maintenance and its connection with aspects of a social sustainability, such as the respect for human rights. Furthermore, it is recommended to deal with measuring the performance equipment management outside the gas industry and the oil industry, as the article [Gruntova 2015] writes. It is also recommended to examine appropriate management tools in this area, such as the 6R method in the article [Holgado 2020]. There is a need for deep knowledge about social and environmental aspects of the maintenance, which would help to build the Industry 4.0 and to develop the predictive maintenance in some organisations. Everything should be judged more holistically than before, as publications state.

\section{DISCUSSION}

The standard ISO 9000 [ISO 9000] is taken as the base of the management system in the article [Castka 2008]. However, it is a dictionary, it should be the ISO 9001 standard [ISO 9001] instead. In the ISO 9001 standard [ISO 9001], people are important for the management system but more from the process management and production point of view. They therefore need the appropriate knowledge for these activities. Awareness is related to the policy, objectives, improvement of the quality management system and the consequences of not meeting the requirements of this system. Thus, de facto, it does not address social responsibility in the true sense of the word. There is a requirement for the organisation to meet the socalled "relevant requirements" according to the production, mainly of customers and stakeholders, the composition of which stems from the related necessary legislation that the organisation must meet in relation to its production (type, volume, critical safety etc.). This area is followed by methods of self-assessment of the organisation's management system. However, they are the subject of another forthcoming publication by the authors of this article. Therefore, only a few aspects related to the topic of that article can be briefly mentioned. The $6 \sigma$ method deals with the elimination of product and process defects. The fundamental focus is on customers. The employee is the input. The EFQM method is a general self-assessment model that tracks the satisfaction of stakeholders. The CAF method is similar, but for public administration and with a simpler evaluation. The WCM method is designed to improve processes and the quality of production and reduce costs for customers. It addresses the development of human resources against the needs of production, not as a human being.

The relationship between the quality management system and social responsibility can be briefly described as follows. Social responsibility consists of 4 parts: workplace, market, environment and public. In this respect, social responsibility is de facto superior to the rest of the system. It conceives the organisation not only in terms of production and as a technical unit. It does not just look at the workplace as a value-adding unit. It perceives the organisation as a complex of socia interpersonal relationships, attitudes and emotions that influence employee satisfaction and thus efficiency, quality of production and to some extent production times and innovation potential of the organisation.

Regarding to the widening gap between rich and poor people, according to the text [Duff 2017], it can be stated that this fact is reflected by feedback in the status quo of some small and medium-sized organisations and in their self-assessment of the management system. The mention of organisations that do not control financial markets in the text [Duff 2017] is comparable to practice findings of authors of this article.

Respecting of the operating license is linked to industry standards, as the article [Martinuzzi 2013] mentions. In connection with the text [Bruno 2020], it is a classic assessment of all aspects of the system - actors, design and the status quo of a road and traffic signs and the current state of the environment, as it follows from the System theory. This can be stated in the sense of social responsibility, that the structure and the surrounding environment influence the change of people's lives. Therefore, it would be appropriate to rely on the classic supply - customer chain, in contrast to the study [Thai 2018]. The article [Holgado 2020] is based on the hierarchical organisational structure of production in organisations. The process approach is not considered at all, which can lead to some nonconformities in the management system.

The search of publications above in this text shows the following. The conception of an organisation's management system is a very broad. It includes all conceivable parts of the organisation. Social responsibility is examined according to the analysis of publications above. The link to production and strategy is especially obvious. Integration of maintenance and environment is promoted. Relationships with customers are dealt with routinely, as are those with suppliers. This also corresponds to the requirements for a quality management system. Employees are treated as resources, not as emotional beings. Communities and regional groups are not commonly considered. Overall, working life is more studied in relation to productivity, logistics and maintenance than as a link to the personal life of the individual. Both the link to the individual and the dynamics of the organisation's environment bring limits to social responsibility that the sector will have to deal with. Looking at the research, most of the aspects addressed by the organisations are mentioned. In relation to the basis, which is the quality management system, whether according to the ISO 9001 standard [ISO 9001] or according to the TQM concept, there is no obvious research on the process approach and its relation to social responsibility. A pattern can be seen in this as an answer to why the social responsibility is not often taken more seriously. Thus, the quality of human life in relation to the tasks of the organisation develops only very slowly. Also, the interfacing with information systems is developing only slowly compared to the needs of integrating this component in building the Industry 4.0. This is likely to have a negative impact on the service sector.

Of the many tasks mentioned above, the authors chose one subtask for further research. It would be appropriate to focus on examining certain aspects of the relationship between the quality management system and the social responsibility, to perceive the end customer of the organisation, but also its employees and their integration into an organisational structure. Relationships to the occupational safety, the maintenance and the environment are also significant in the environment of the Czech Republic. 


\section{THE CONCEPT OF THE SOCIAL RESPONSIBILITY}

The social responsibility is most often understood as the composition of the economy, the employees, and the environment. The second option is to add the public as a fourth component, such as the text [Author2 2008] states. The economy is focused on the profit of organisations and subsequently on participation in local, state, or international market and on the elimination of corruption. The environmental protection is not just about a sorting waste and renewables. This also includes the whole area of care for ecosystems, air, soil and water and the monitoring of other factors such as noise and so on. The care for employees is provided in the spirit of a gender equality and in the respect for human rights and for the right to work. However, these are an occupational safety, education and raising of living standards. The dialogue with the public and the respect for local community are a new part relatively. The requirement of respect for stakeholders is based on technical standards for management systems. Problematic parts of the social responsibility are longevity, voluntariness, and credibility. An interest of most countries focuses on production costs and delivery times. In addition, the quality is assessed, but usually only for end customers. However, they are downplayed in a supply chain according to their requirements. However, rules of prof. Imai add the security and the ethics to these 3 parts. The safety is given by health laws. The ethics is often forgotten. The following conclusions are based on the analysis of the authors' existing knowledge on this issue and then by deduction.

The concept of social responsibility is expanding. The quality refers to a product in the social responsibility. However, the need is also to respect the quality of the management system, which is not included. The maintenance can be taken into the social responsibility relatively easily. In contrast, this is not a simple compared to the process approach. Aspects of the process approach clearly support the social responsibility. However, the social responsibility does not primarily support the process approach, because it is not based on independence, flexible organisational structures, it does not address the way of management so much if it does not directly violate rights of employees and it does not rely on the stability of the management system of the organisation. In short, these findings show further integration possibilities of management systems and possibilities of improving of an internal context in organisations.

\section{CASE STUDY}

The article is based on a case study of the management system in the organisation in the Czech Republic according to the bachelor thesis [Kolar 2020]. The organisation has a line organisational structure. It is a medium-sized organisation, which operates in the glass industry. The production is a serial. Emphasis is based on customer requirements. Equipment in the organisation consists of $2 / 3$ old types and $1 / 3$ new types. Failure maintenance is applied for the most of old equipment and preventive maintenance is applied to new equipment. Management system certificates were issued according to the standard ISO 9001 for quality [ISO 9001] and according to glass industry standards.

As a part of the research of the organisation, the procedure of production and its material and information flows were monitored. Following nonconformities emerged from the observation of the management system in organisation and after the inspecting to documentation of the organisation.
There are problems with the commissioning of a production line. There is a large staff turnover. The maintenance is not almost documented. There is a damage of products (for example there are: errors in entering customer requirements, dirt, defects and scratches, manufacturing errors, cracks during storage, packaging errors and other errors). There are semifinished products sought also due to an unstable spatial structure of the organisation. Employees are not sufficiently trained. Production is a slow and there are sometimes problems to keep the deadline of orders. Employees do not know and do not perform a basic maintenance of equipment. Employees are not substitutable.

Production nonconformities were analysed according to prices of complaints from customers per calendar month. Defects and scratches proved to be the most problematic here. Furthermore, these nonconformities were investigated by using the Pareto analysis at the $80 \%$ level, as the Figure 1 . shows. There are came out: defects and scratches, manufacturing errors and cracks during storage, as a significant minority of this diagram.

Subsequently, risks of production stages were examined with the help of the FMECA analysis. The evaluation was performed on points based on assigned scale from 0 to 5 points. The 9 most serious risks were selected from identified risks by using the Pareto's rule, as the Table 1. presents (in the table: $\mathrm{O}$ is occurrence, $\mathrm{S}$ is importance, $\mathrm{D}$ is detection and RPN is the risk number). The looking at graph and table brigs that the most of listed risks (specifically 7 out of 9) lead to the emergence of two most important types of complaints. Key solutions are seen the training of employees and a correct explanation of the content of their work. Actions have been proposed for the remaining of these risks, which should reduce or prevent their occurrence. Furthermore, aspects of the process approach, the maintenance and the social responsibility were evaluated. Even in this case, the FMECA analysis was used with an assigned scale of up to maximum 3 points.

Criteria were evaluated for the process approach: form of management, unit (that is 1 piece of the glass), communication, organisational structure, decision-making, independence and individual. The result of this criterion was excellent. The created process map helped to detect the status quo. The advantage was a free communication among employees of the organisation and thus better sharing of experience. The decision-making based on customer requirements and processes is an important, not by individual activities. The promoting of independence and responsibility of employees had a positive effect and influenced their motivation and subsequent quality of products.

Criteria for the maintenance management were evaluated: verification of adjustments, availability of instructions, use of statistical methods, determination of a key equipment and their maintenance, maintenance planning, availability of spare parts, existence of maintenance documentation and maintenance prediction. The result of this criterion was below average. The maintenance of equipment has a significant effect on a production efficiency. A predominant maintenance after failure and the absence of equipment maintenance documentation has an opposite effect. It is also necessary to identify key components of equipment for a good planning of spare parts. It turned out that maintenance employees were not equipped with sufficient documentation and with working tools. Ordinary employees do not perform a routine minor maintenance on the equipment. 
Average number of discrepancies pcs/month

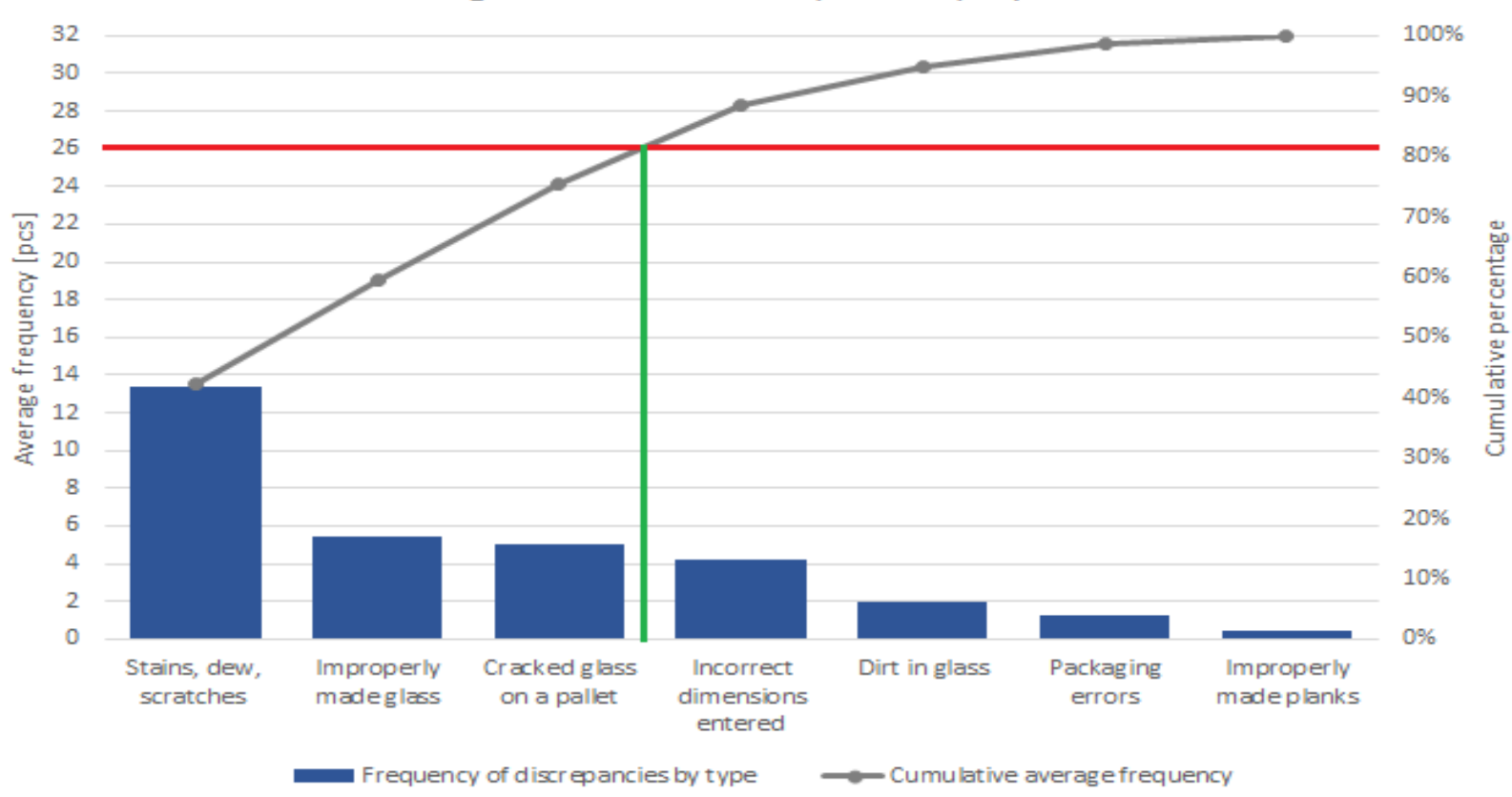

Figure 1. The Pareto analysis of average number of nonconformities, originally based on the publication [Kolar 2020].

\begin{tabular}{|c|c|c|c|c|}
\hline $\begin{array}{l}\text { Phase of } \\
\text { production }\end{array}$ & Potential risk & 0 & $S|| D$ & ||RPN \\
\hline Ordering & Wrong data & 3 & $5 \longdiv { 4 }$ & 60 \\
\hline Puttying & $\begin{array}{l}\text { Exceeding the critical limit of } \\
\text { the putty }\end{array}$ & 3 & 5|| 4 & || 60 \\
\hline Gluing the frame & Mess in the glass & 4 & 43 & 48 \\
\hline Gluing the frame & Improperly glued frame & 3 & \begin{tabular}{|l|l|l|l|}
4 & 4 \\
\end{tabular} & 48 \\
\hline Puttying & Dirt, poor quality & 4 & 3 & 48 \\
\hline Puttying & Machine failure & 4 & $5 \mid 2$ & 40 \\
\hline Inserting glass & Improperly rotated glass & 2 & \begin{tabular}{|l|l|l}
4 & 4 \\
4
\end{tabular} & 32 \\
\hline Dispatch & Documentation error & 2 & 44 & 32 \\
\hline Puttying & Bubbles in the putty & 3 & 33 & 27 \\
\hline
\end{tabular}

Table 1. FMECA analysis of serious risks in the phase of production, originally based on the publication [Kolar 2020].

Criteria for the social responsibility were evaluated: social (discrimination, education, a protective aids), environmental (a waste sorting, waste of materials and use of renewable resources), public (a professional state training, industrial zone, and outsourcing) and economic (invoice dates). The result of this criterion was excellent. The social responsibility helps to create good working conditions in the organisation. It helps tackle a gender inequality and bullying in workplaces. It justifies the use of personal protective working aids. The goal was to reduce staff turnover and to create a stable team. A waste sorting and a material waste dominate in environmental area in the organisation. A considerable attention was given to a documentation of social responsibility and its management.

The following can be stated. The continuity of production and thus the quality of production has increased after the production. The quality of production is linked to the social responsibility. The proof is that the improvement of the internal context of the organisation regarding independence, occupational safety and motivation of employees led to a decrease in the number of nonconformities, especially the production in the period under review.

In the last year, the organisation, like others, has been facing the COVID-19 crisis. Constantly changing epidemiological measures complicate the production process in the organisation. They are unpredictable. The government of the state does not simplify this situation for its organisations. These changes thus require adjustments in a material flow and an information flow of the organisation to strengthen safety and to ensure the ability to produce. At the same time, cost items for them are growing. A part of the staff was transferred to the home office. There are technicians (technology and product development) and traders. However, this situation brings, and aids are required in the production process that many employees are hindered in their work in the production process and in maintenance and so on. The repeated requirement to test all employees and to impose quarantines on teams makes a very difficult situation for a production planning. An information sharing is hampered by employees' fear from loss of their position. Another major problem is the closure of transport routes between districts or states, which they complicate supply - customer chains. Further, the political crisis in certain regions is deepening. In other words, the delivery of raw materials and spare parts to the organisation and the sale of finished products to customers on time are hampered. The Ishikawa diagram (on the Figure 2.) has been processed. It shows possible causes of nonconformities in the management system of the organisation. The current solution was focused on the sub-causes of materials, methods, and employees. In the following period, these causes should be monitored in detail in connection with the COVID-19 crisis, which it affects production, quality, and social responsibility in the organisation over the long term. Stable and reliable supplier - customer relationships among organisations and their good payment morale are considered 


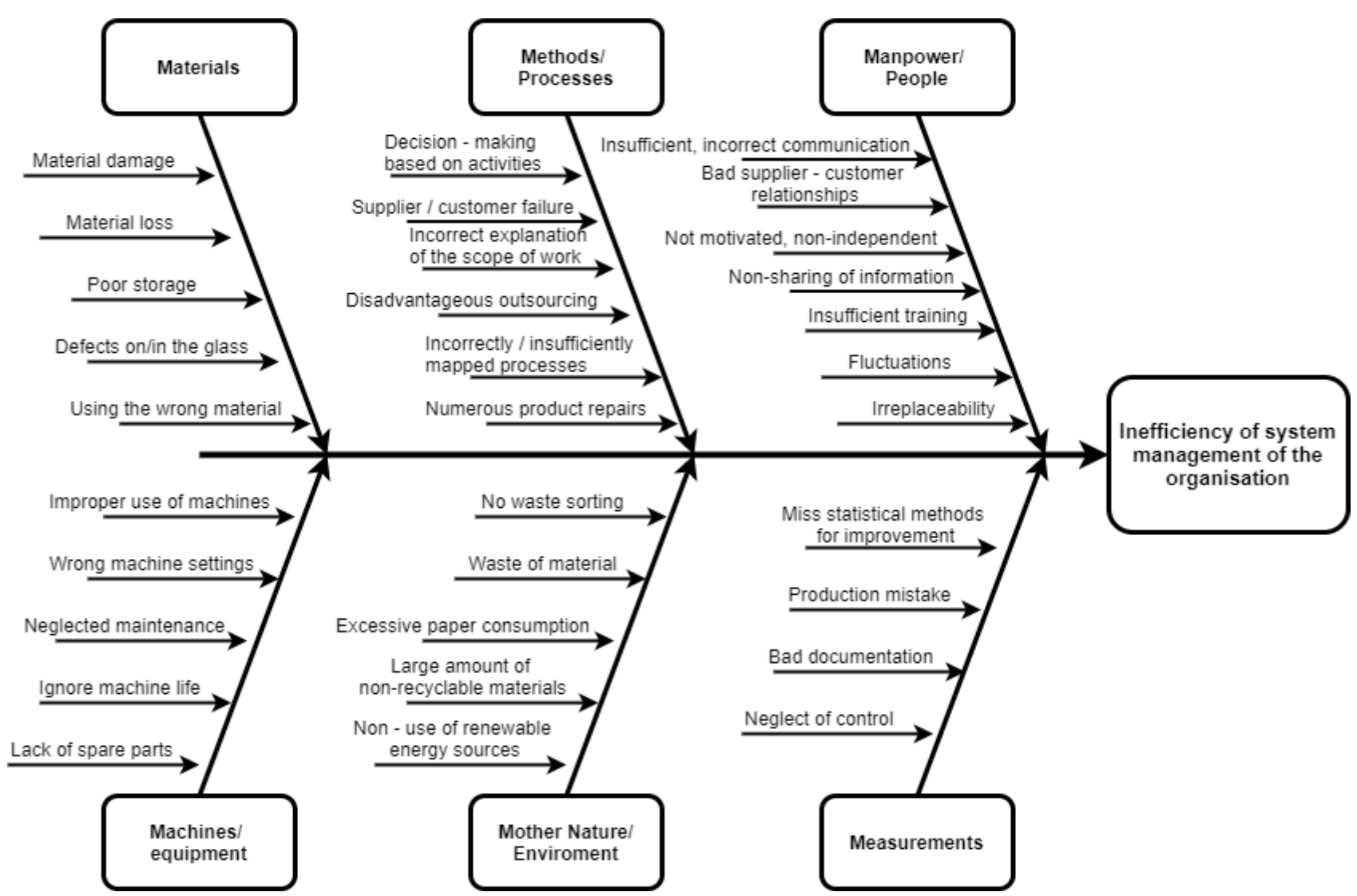

Figure 2. The Ishikawa diagram of causes of problems in the organisation. Own of authors.

now to be a key. It is also advisable to have loyal customers who regularly purchase products.

\section{CONCLUSIONS}

The conclusion is based on the findings of the case study and the findings of the authors from dealing with similar issues in other organisations, although this was not a priority task in these organisations. Based on the performed comparative analysis of previous and current conditions in the organisation, operating outside the oil and gas industry, and according to a theoretical basis of the system theory, the following can be stated. The environmental aspect, as a part of the social responsibility, is now declining. On the contrary, it strengthens the area of a work safety. The area of care for employees is narrowed down to respecting the protection of health and human rights. Staff training is weakened probably because of the COVID-19 crisis and the subsequent reallocation of costs in organisations. Work-life balance support has stalled. It was determined empirically from qualitative characters of the management system. The quality of production is a crucial and it relies even more clearly on a stable work of the maintenance. However, both are hampered by market failures and traffic flows between organisations. Links of the organisation to the local market are more advantageous than to the global market. Costs of the organisation to ensure occupational safety and epidemiological requirements set by the state are growing now. There is a link between production quality and social responsibility. However, it was not possible to explore social responsibility in more depth given the knowledge of the organisation's staff. In the organisation, the importance of the social responsibility lies somewhere in the middle and therefore is not a priority. Overall, despite the outcome of the organisation, a social responsibility situation can be described

as weakened. It would help to include aspects of the process approach and strengthen maintenance of equipment and systems. A holistic concept of the management system in the organisation, based on the quality of production, the maintenance of equipment, the process approach, and the social responsibility, shows to be a long-term beneficial for the internal context of the organisation and thus for the strengthening its competitiveness. The presented study can serve as a simple tool for assessing the social maturity of an organisation and its relationship to other parts of an integrated management system, including quality and maintenance.

The relationship between the social responsibility and the quality management should be further explored in the context of changes of the substantial environment of organisations.

\section{ACKNOWLEDGMENTS}

This work was supported with institutional support for long term strategic development of the Ministry of Education, Youth and Sports of the Czech Republic.

\section{REFERENCES}

[Author1 2020] Authors. Megafactories. Paper mill Gműnd. Document, Germany, TV Prima ZOOM, 2020-12-09.

[Author2 2008] Authors. Social responsibility of firms. In: Businessinfo.cz, 2/2008. [Online.] [Citation: 202102-17.] Available from: https.//businessinfo.cz/navody/spolecenskaodpovednost-firem-pruvodce

[Bruno 2020] Bruno, M. and Nikolaeva, A. Towards a maintenance-based approach to mode shift: Comparing two cases of Dutch cycling policy using social practice theory. In: Journal of Transport Geography, Vol. 86, Issue 0, 2020. ISSN 0966-6923. [Online.] [Citation: 2021-02-17.] Available from: 
https://www.researchgate.net/profile/Anna_Nikola eva/publication/342346818_Towards_a_maintenan ce-

based_approach_to_mode_shift_Comparing_two_c ases_of_Dutch_cycling_policy_using_social_practic e_theory/links/5ef0cd03a6fdcc73be945813/Towar ds-a-maintenance-based-approach-to-mode-shiftComparing-two-cases-of-Dutch-cycling-policy-usingsocial-practice-theory.pdf

[Castka 2008] Castka, P. and Balzarova, M.A. Adoption of social responsibility through the expansion of existing management systems. In. Industrial Management and Data Systems, Vol. 108, No.3, 2008, pp. 297309. ISSN 0263-5577. [Online.] [Citation: 2021-0217.] Available https.//doi.org/10.1108/02635570810858732

[Drozyner 2020] Drozyner, P. The impact of the implementation of management system on the perception of role and tasks of maintenance services and effectiveness of their functioning. In: Journal of Quality in Maintenance Engineering, Vol. Ahead of print, No. Ahead of print, 4/2020. ISSN 1355-2511. [Online.] [Citation: 2021-02-17.] Available from: https://doi.org/10.1108/JQME-092019-0089

[Duff 2017] Duff, A. Corporate social responsibility as a legitimacy maintenance strategy in the professional accountancy firm. In: The British Accounting Review, Vol. 49, Issue 6, 2017, pp. 513-531. [Online.] [Citation: 2021-02-17.] Available from: https://www.sciencedirect.com/science/article/pii/ S0890838917300392

[Gruntova 2015] Gruntova Kolingerova, H. Application of performance evaluation outcomes. In. Trendy v podnikání - Business trends, vědecký časopis Fakulty ekonomické ZČU v Plzni, 2015, No.3, pp. 1827. ISSN 1805-0603.

[Holgado 2020] Holgado, M., et al. Exploring the impacts and contributions of maintenance function for sustainable manufacturing. In: International Journal of Production Research, Responsible and Sustainable Manufacturing, Vol. 58, Issue 23, 2020, pp.7292-7310. [Online.] [Citation: 2021-02-17.] Available from: https://www.tandfonline.com/doi/full/10.1080/002 07543.2020 .1808257

[ISO 9000] Standard CSN EN ISO 9000: 2016. (010300) Quality Management Systems - Basic principles and vocabulary. Prague: UNMZ, 2016.

[ISO 9001] Standard CSN EN ISO 9001: 2016 (01 0321) Quality Management Systems - Requirements. Prague: UNMZ, 2016.

[ISO 26000] Standard ČSN ISO 26000: 2011 (010390) Guidelines for social responsibility. Prague: UNMZ, 2011.

\section{CONTACTS:}

Ing. Vera Pelantova, Ph.D.

Technical university of Liberec, Faculty of Mechatronics, Informatics and Interdisciplinary Studies, MTI

Studentska 2, 461 17, Liberec 1, Czech Republic

485353 520, vera.pelantova@tul.cz,www. tul.cz
[Kolar 2020] Kolar, D. The Ensuring of Quality Glass Production. [Bachelor work.] Liberec: Technical university of Liberec, FM, MTI, 2020.

[Martinuzzi 2013] Martinuzzi, A. and Krumay, B. The Good, the Bad, and the Successful - How Corporate Social Responsibility Leads to Competitive Advantage and Organizational Transformation. In: Journal of Change Management, Vol. 13, Issue 4, 2013, pp. 424-443. [Online.] [Citation: 2021-02-17.] Available from:

https://www.tandfonline.com/doi/full/10.1080/146 97017.2013.851953

[Pelantova 2014] Pelantova, V. and Havlicek, J. Integration and Systems Management. Liberec: Technical university of Liberec, FM, MTI, 2014. ISBN 978-80-7494-164-1.

[Rakyta 2014] Rakyta, M., et al. L. Increasing the performance of production systems through maintenance planning. In: International Conference: Manufacturing Systems Today and Tomorrow, Liberec, 11/2014. [Online.] [Citation: 2021-02-17.] Available from: Increasing-the- performance-ofproduction-systems-through-maintenanceplanning.pdf

[Thai 2018] Thai, V.V., et al. Interaction impacts of corporate social responsibility and service quality on shipping firms 'performance. In: Transportation Research Part A: policy and Practice, Vol. 113, 7/2018, pp. 397-409. [Online.] [Citation: 2021-02-17.] Available from:

https://www.sciencedirect.com/science/article/pii/ S0965856417300162\#

[Toussaint 2020] Toussaint, J.S., et al. Lean, Shingo, and the Baldridge framework: A comprehensive method to achieve a continuous improvement management system. In. NEJM Catalyst Innovations in Care Delivery, Vol. 1, No. 3. [Online.] [Citation: 2021-0217.] Available from: https://catalyst.nejm.org/doi/10.1056/CAT.20.0114

[Yee 2020] Yee, R.W.Y. et al. Work-life management for workforce maintenance: A qualitative comparative study. In: Journal of Business Research, Vol. 121, 10/2020, pp. 329-337. [Online.] [Citation: 2021-0217.] Available from: https://www.sciencedirect.com/science/article/pii/ S0148296320305919

[Yunusa-Kaltungo 2021] Yunusa-Kaltungo, A. and Labib, A. A hybrid of industrial maintenance decision making grids. In: Production Planning and Control, The Management of Operations, Vol. 32, Issue 5, 2021, pp. 397-414. [Online.] [Citation: 2021-02-17.] Available from: https://doi.org/10.1080/09537287.2020.1741046

Bc. Dominik Kolar

Technical university of Liberec, Faculty of Mechatronics, Informatics and Interdisciplinary Studies, MTI

Studentska 2, 461 17, Liberec 1, Czech Republic

domo.kolar@gmail.com,www.tul.cz 